\title{
A Novel Compact CP Antenna with Wide Axial Ratio Bandwidth for Worldwide UHF RFID Handheld Reader
}

\author{
Waleed Abdelrahim Ahmed (i) and Feng Quanyuan (i) \\ School of Information Science and Technology, Southwest Jiaotong University, Chengdu 611756, China \\ Correspondence should be addressed to Feng Quanyuan; fengquanyuan@163.com
}

Received 20 January 2019; Revised 18 February 2019; Accepted 3 March 2019; Published 2 May 2019

Academic Editor: Ikmo Park

Copyright ( 2019 Waleed Abdelrahim and Feng Quanyuan. This is an open access article distributed under the Creative Commons Attribution License, which permits unrestricted use, distribution, and reproduction in any medium, provided the original work is properly cited.

\begin{abstract}
This study presents a novel compact circularly polarized antenna for universal ultrahigh-frequency (UHF) radio-frequency identification (RFID) handheld reader applications. The antenna is composed of a coplanar waveguide (CPW) L-shaped feedline mounted at the right edge of the square slot at the bottom of the ground plane to realize a circular polarization; a horizontal stub protruded from the right side of the square slot towards the slot centre, and a vertical stub is mounted at the lower left of the square slot. The designed antenna printed on one ground plane layer of a low-cost FR4 substrate with an overall size of 120 $\times 120 \times 1.6 \mathrm{~mm}^{3}$. The measurement results show indicate that the fabricated antenna achieves a wide axial ratio (AR) bandwidth of $460 \mathrm{MHz}(818-1278 \mathrm{MHz})$, wide impedance bandwidth of $54.6 \%(630-1103 \mathrm{MHz})$, and a measured peak gain of $4.0 \mathrm{dBi}$. The proposed antenna is a good candidate for compact universal UHF RFID handheld reader applications (840-960 MHz).
\end{abstract}

\section{Introduction}

Radio-frequency identification (RFID) is an auto-ID technology that uses radio-frequency waves for the purpose of tracking and identifying objects in supply chains, access control, warehouses, commerce, and so on $[1,2]$. Compared to other kinds of identification technologies, RFID has been receiving much attention due to its advantages, such as a high data transfer rate, longer information storage capability, and high reliability. RFID technology can be categorized into four categories according to its use in different frequency bands, namely, low-frequency (LF), highfrequency (HF), ultrahigh-frequency (UHF), and microwave RFID systems. Recently, RFID systems, especially in the global UHF band from 840 to $960 \mathrm{MHz}$ (13.3\%), have gained popularity due to the advantages of high data transfer rate, fast reading speed, and long detection range $[3,4]$.

Basically, the RFID system comprises an RFID tag (tag antenna+an application-specific integrated circuit (ASIC)), an RFID reader device (reader with its antenna), and a host computer for the purpose of information processing. Briefly, the reader sends a radio-frequency signal to the RFID tag antenna using an antenna and receives a modulated signal back from the tag. To receive the radio-frequency signal from the reader antenna, the RFID tag must be into the reading zone of the reader antenna [5].

In practical usage, the UHF RFID tag antennas usually are linearly polarized (LP) and the UHF RFID tags are normally oriented arbitrarily. To ensure the reliability of the communications between RFID reader devices and RFID tags, a reader antenna with a circularly polarized (CP) characteristic is highly required [6]. The reader antenna for RFID systems are one of the most significant parts of the RFID systems. Sometimes, their inability to accommodate new operating scenarios can restrict the RFID system performance as a whole. UHF RFID handheld reader applications require a compact antenna with low profile and light weight.

Over the past years, several $\mathrm{CP}$ reader antennas such as microstrip antennas $[7,8]$, patch antennas $[9,10]$, and stacked-architecture antennas $[11,12]$ that were designed with various techniques to operate in the UHF RFID range 
have been investigated. However, the aforementioned RFID reader antennas [7-12] are unable to cover the global UHF RFID band ( $840 \mathrm{MHz}$ to $960 \mathrm{MHz}$ ) owing to their narrow impedance and axial ratio (AR) bandwidths, relatively large sizes, and incompatibility with a handheld reader or application which needs to a have a small-sized antenna.

Some reader antennas demonstrate a big gain, but their sizes are too large to use in handheld reader applications. Compact antennas that have simple structures, inexpensive, and easy to fabricate are tremendously needed for UHF RFID handheld reader applications. Subsequently, lowering the fabrication cost of the RFID reader antennas and simplifying their design are an interesting target for many researchers and manufacturers in this field. For RFID system implementation and cost reduction, designing a universal reader antenna with acceptable performance throughout the universal UHF RFID range would be beneficial. Slot antennas have the merits of a small size, easy to design, an inexpensive, and wide frequency bandwidth. In recent years, two similar CP slot antennas have been presented, such as the planar broadband antenna with a square slot and F-shaped feedline to operate in the UHF RFID band in [13] and wideband universal CP reader antenna with a circular slot and fed by a coplanar waveguide (CPW) L-shaped feedline in [14]. However, both antennas have a relatively large volume and narrow impedance and axial ratio bandwidths compared to the proposed antenna. A planar, lightweight, crossed-dipole antenna with CP radiation is introduced for application in a UHF RFID handheld reader in [15], and a CP monopole antenna using a short-circuited sleeve strip for a UHF RFID reader is presented in [16]; both designs have small sizes and printed on a single layer of ground plane. Nevertheless, both antennas have a narrow axial ratio bandwidth and low measured gain, and do not cover the global UHF RFID frequency range.

In this study, we propose a novel low-profile CP reader antenna printed on a low-cost FR-4 material that has a small size and covers the entire UHF RFID band easily. The antenna consists of a CPW L-shaped feedline mounted at the right edge of the square slot at the bottom of the ground plane; a horizontal stub protrudes from the right side of the square slot towards the slot centre, and a vertical stub is placed at the lower left of the square slot. The proposed antenna designed as a universal UHF RFID handheld reader with good peak gain, wider impedance and AR bandwidths, good impedance matching, and compact size. Meanwhile, the antenna has a simple configuration, a planar single-layer ground plane structure, and simple fabrication process.

Details of the proposed universal UHF RFID reader antenna design are described, and a comparison between the simulation and experimental results in terms of reflection coefficient $\left|S_{11}\right|$ bandwidth, AR bandwidth, peak gain, and radiation pattern is presented and discussed as well. A parametric study for the significant parameters of the designed antenna as well as a comparison between the proposed antenna and other antennas operating in the UHF RFID band is also conducted.

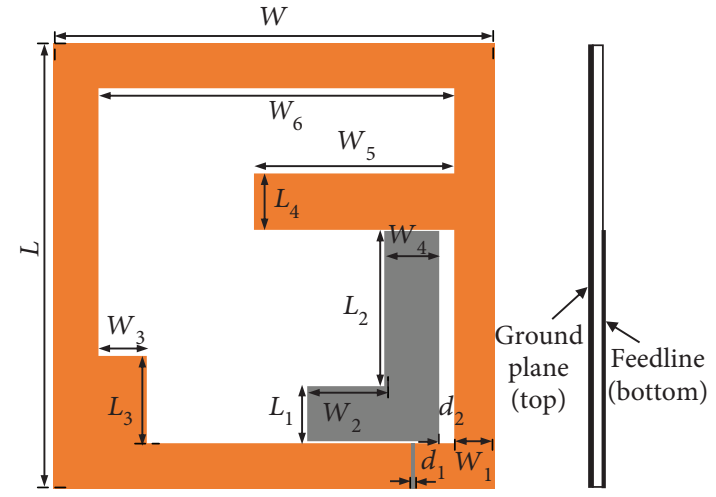

FIGURE 1: Geometry of the proposed antenna.

TABLE 1: Optimal dimensions of the proposed antenna.

\begin{tabular}{lccccc}
\hline Parameter & Value & Parameter & Value & Parameter & Value \\
\hline$L$ & 120 & $W$ & 120 & $W_{5}$ & 54 \\
$L_{1}$ & 16 & $W_{1}$ & 11 & $W_{6}$ & 96 \\
$L_{2}$ & 42 & $W_{2}$ & 21 & $d_{1}$ & 1.2 \\
$L_{3}$ & 24 & $W_{3}$ & 13 & $d_{2}$ & 3.5 \\
$L_{4}$ & 15 & $W_{4}$ & 15 & & \\
\hline
\end{tabular}

\section{Antenna Configuration}

The configuration of the proposed compact slot antenna with its dimension is shown in Figure 1. The proposed antenna is fed via a SMA connector by a CPW feedline at the bottom side of the FR4 substrate (loss tangent $\delta=0.02$, relative permittivity $\varepsilon_{\mathrm{r}}=4.4$, and substrate thickness of $1.6 \mathrm{~mm}$ ). The CPW feed has a signal strip line with a width of $1.2 \mathrm{~mm}$. One end of the signal strip line was connected to the inverted L-shaped feedline, whereas the other end was connected to a coaxial SMA connector. A wide square slot of $96 \times 96 \mathrm{~mm}^{2}$ is extracted from the basic square slot on the top side of the ground plane. An inverted L-shaped feedline is mounted on the right side of the lower ground plane to realize the $\mathrm{CP}$ characteristic. The proposed antenna has an overall size of $120 \times 120 \mathrm{~mm}^{2}$. The optimal dimensions of the proposed antenna are listed in Table 1.

The CP characteristic can be realized when two orthogonal $E$ vectors (the complex voltage in the horizontal $\left(E_{\mathrm{Hor}}\right)$ and vertical $\left(E_{\mathrm{Ver}}\right)$ plane) of equal amplitude are excited with a phase difference of $90^{\circ}$ [17]. To clarify the CP performance of the proposed antenna, Figure 2 demonstrates the evolutionary steps of the proposed antenna and Figure 3 shows the simulation results of the impedance and AR bandwidths for Antennas 1-4. There are four stages (Antenna 1, Antenna 2, Antenna 3, and Antenna 4) when designing an antenna to achieve the proposed antenna. In this article, Antenna 4 is the final design for the proposed antenna. Firstly, Antenna 1 consists of a wide rectangular slot in the ground plane with a CPW inverted L-shaped feedline at the centre of the slot towards the $-y$ axis direction. The L-shaped feedline was used to generate more than one 


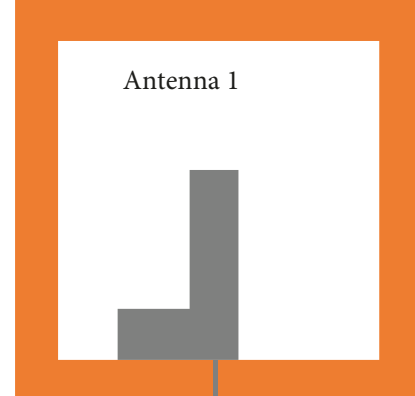

(a)

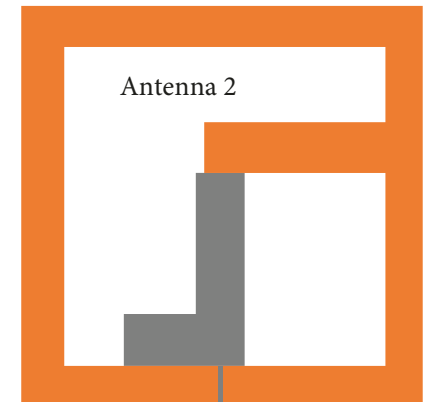

(b)

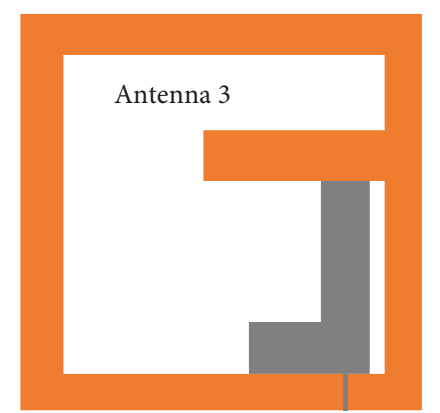

(c)

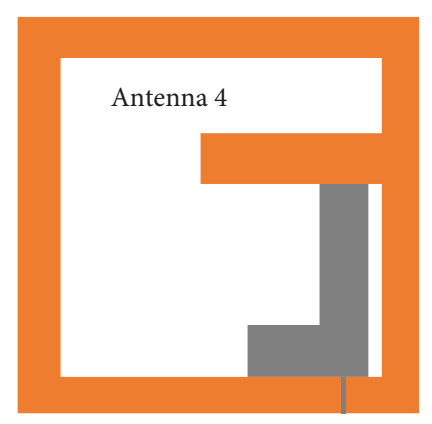

(d)

Figure 2: Evolutionary steps of the proposed antenna.

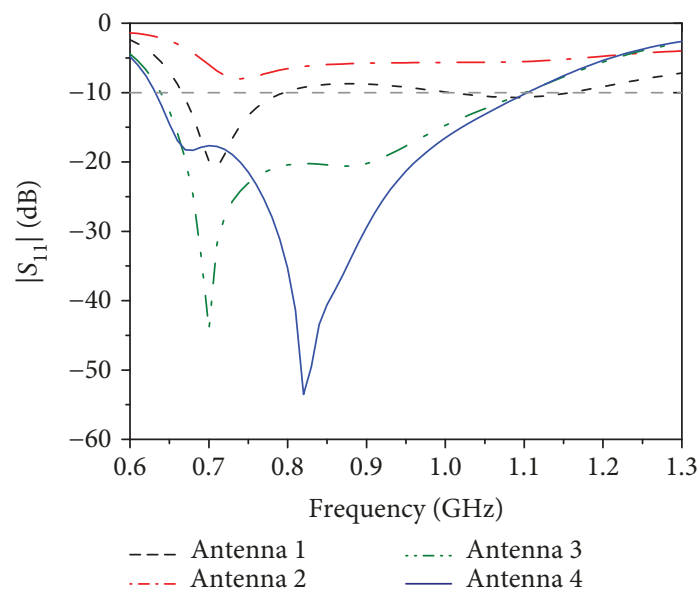

(a)

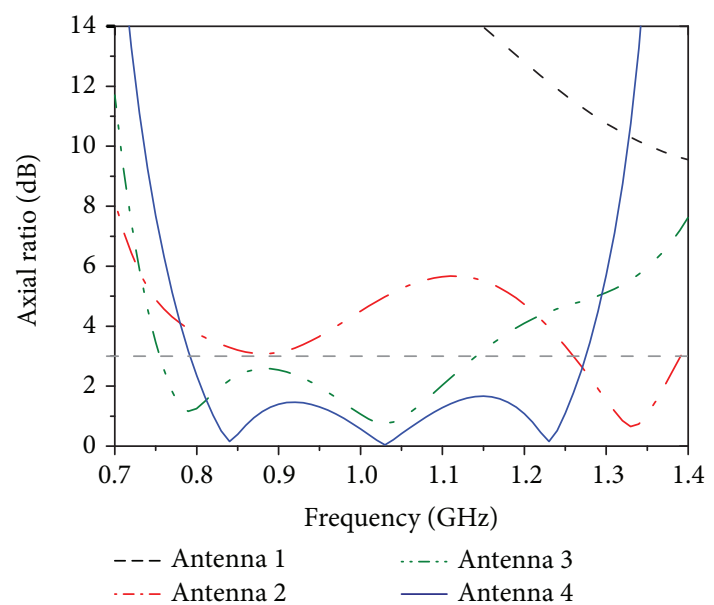

(b)

FIgURE 3: Simulated (a) $S_{11}$ bandwidth and (b) AR bandwidth results for Antennas 1-4.

resonant frequency. Although Antenna 1 is linearly polarized (with an AR bandwidth around $9 \mathrm{~dB}$ ), Antenna 1 has a wide impedance bandwidth, as shown in Figure 3. Then, a horizontal stub (along the $-y$ axis) protruded at the right side of the slot toward the slot centre to achieve Antenna 2. Because the $E_{\mathrm{Hor}}$ of the horizontal stub $\left(L_{4} \times W_{5}\right)$ and $E_{\mathrm{Ver}}$ of the inverted L-shaped feedline have a $90^{\circ}$ phase difference, a broadband CP wave was realized. Although the impedance bandwidth of Antenna 2 was distorted at higher than $-10 \mathrm{~dB}$, the $\mathrm{CP}$ performance is much better. As shown in Figure 3(b), the simulated $3 \mathrm{~dB}$ AR bandwidth is out of the UHF RFID range. In the third stage, to adjust the $\mathrm{CP}$ bandwidth on the desired band (UHF RFID band from $840 \mathrm{MHz}$ to $960 \mathrm{MHz}$ ) as well as improve the impedance bandwidth significantly, the inverted L-shaped feedline is shifted carefully to the right edge of the rectangular slot underneath the protruding vertical stub to obtain Antenna 3. The results of this stage are a good impedance bandwidth characteristic (from $638 \mathrm{MHz}$ to $1102 \mathrm{MHz}$ ) and good $3 \mathrm{~dB}$ axial ratio bandwidth (from $755 \mathrm{MHz}$ to $1143 \mathrm{MHz}$ ) which easily covered the entire UHF RFID band. Finally, to achieve additional improvement to the antenna performance as a whole, a vertical stub $\left(L_{3} \times W_{4}\right)$ was added to the structure at the lower left of the square slot, as shown in Antenna 4 (proposed antenna). Antenna 4 shows an impedance bandwidth characteristic of $472 \mathrm{MHz}(632-1104 \mathrm{MHz})$ and AR bandwidth of $484 \mathrm{MHz}(792-1276 \mathrm{MHz})$.

To investigate the $\mathrm{CP}$ behaviour, the surface current distributions at $900 \mathrm{MHz}$ on the square slot and the L-shaped feedline are depicted in Figure 4, illustrating the current direction behaviour at different phases of $0^{\circ}, 90^{\circ}, 180^{\circ}$, and $270^{\circ}$. With reference to Figure 4 , it is observed that the current distributions on the inverted L-shaped feedline and the square slot are travels in the clockwise direction as the phase angle increases by $90^{\circ}$, exciting a left-hand circularly polarized (LHCP) radiation.

\section{Parametric Studies}

Parametric studies are conducted to provide additional detailed information about the antenna designing and optimization process. Due to a good agreement between the simulation and measurement results for all antenna parameters, the parametric study is carried out by simulation results as well. The parameters under study include the width of the signal strip line $\left(d_{1}\right)$, the distance between the L-shaped feedline and the right edge of the square slot $\left(d_{2}\right)$, the length of the vertical stub of the L-shaped feedline $\left(L_{2}\right)$, and the length of the horizontal stub $\left(W_{5}\right)$. To understand the influence of these parameters on the performance of the proposed 

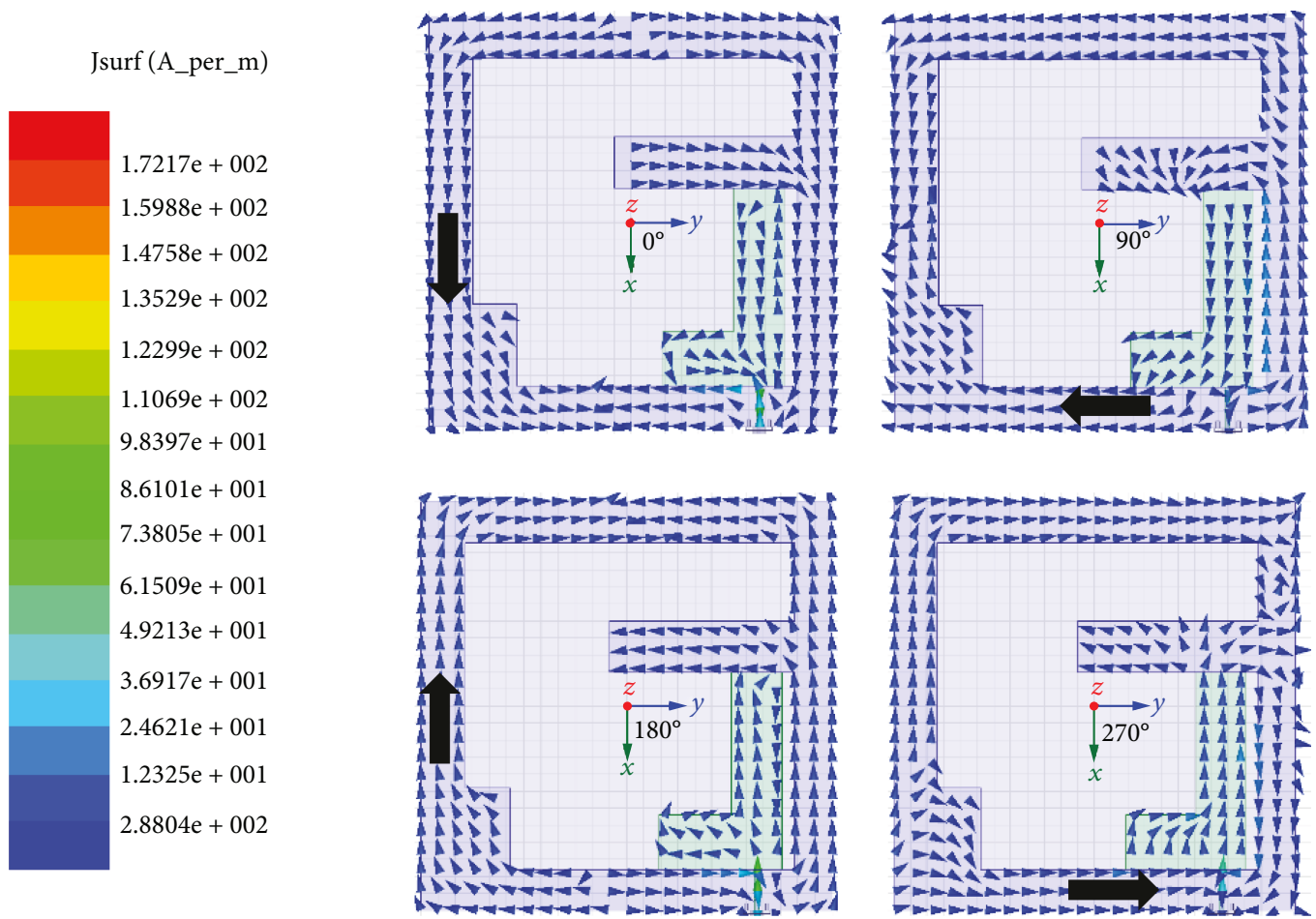

FIgURe 4: Distribution currents of Antenna 4 at $900 \mathrm{MHz}$.

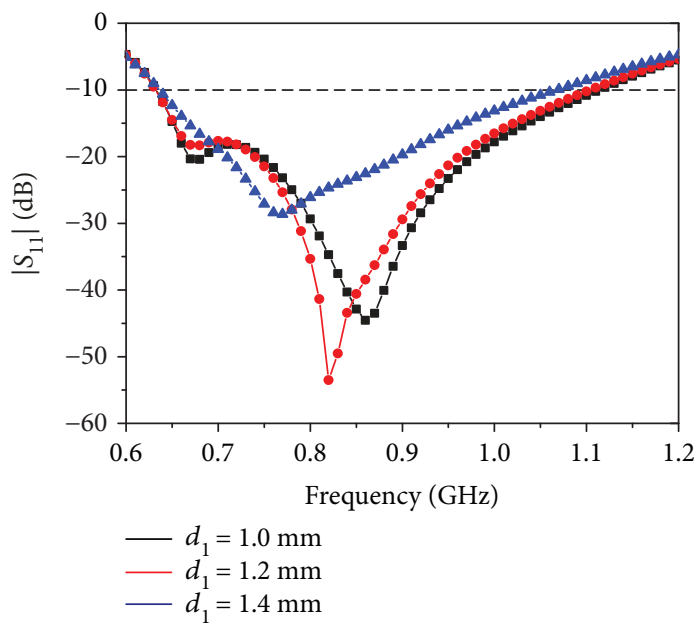

(a)

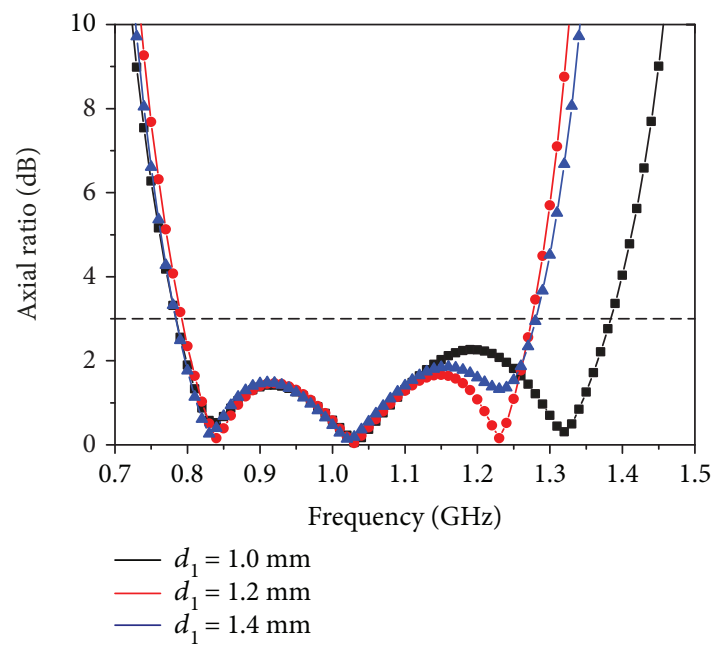

(b)

FIgURE 5: Simulated $\left|S_{11}\right|$ and AR results for different signal strip widths $\left(d_{1}\right)$.

antenna, only one parameter will be varied, while the other parameters will be fixed.

3.1. Effects of the Width of the Signal Strip Line $d_{1}$. The influence of the width of the signal strip line $\left(d_{1}\right)$ on the performance of the antenna is illustrated in Figure 5. It is found that the value of $d_{1}$ just changes the resonant frequency and the impedance matching of the antenna reflection coefficient, but it does not change the start and end bands of the reflection coefficient bandwidth considerably. With reference to the influence of $d_{1}$ on the axial ratio bandwidth, it is found that $d_{1}$ changes the axial ratio bandwidth but widens it only when $d_{1}=1.0 \mathrm{~mm}$.

3.2. Effects of the Parameter $d_{2}$. Figure 6 shows the effect of the distance between the L-shaped feedline and the right edge of the square slot $\left(d_{2}\right)$ on the performance of the antenna. With reference to Figure 6(a), it can be inferred that the resonant frequency of the reflection coefficient bandwidth is increased when the value of $d_{2}$ increased. The study shows that the axial ratio bandwidth shifted slightly to lower frequencies when $d_{2}=2.5 \mathrm{~mm}$ and $3.5 \mathrm{~mm}$, and the wider axial 


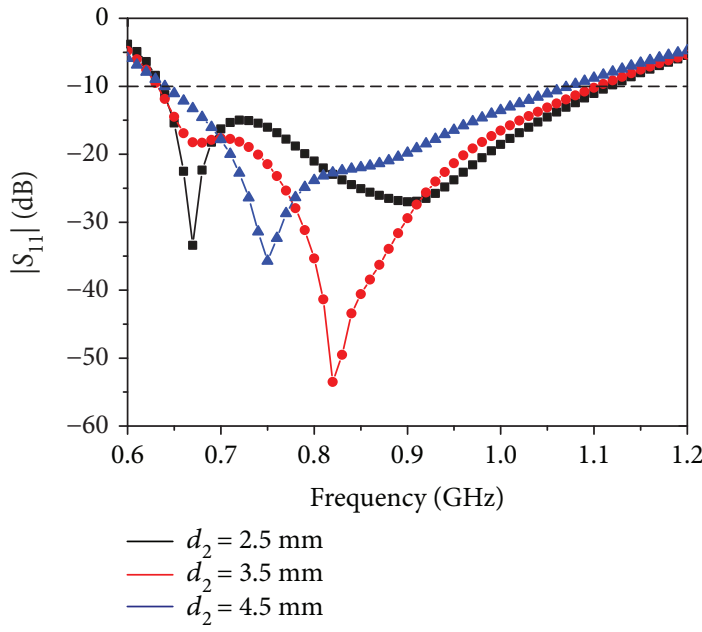

(a)

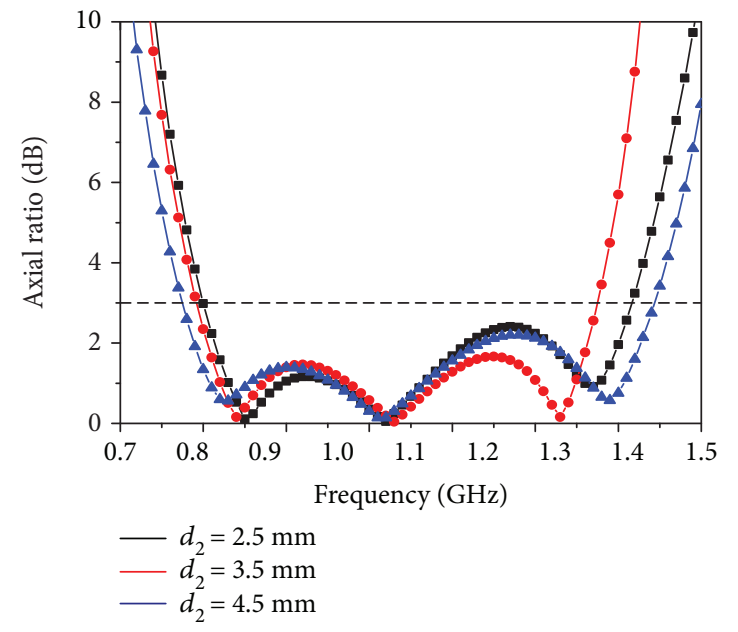

(b)

FIGURE 6: Simulated $\left|S_{11}\right|$ and AR results for different distances $\left(d_{2}\right)$.

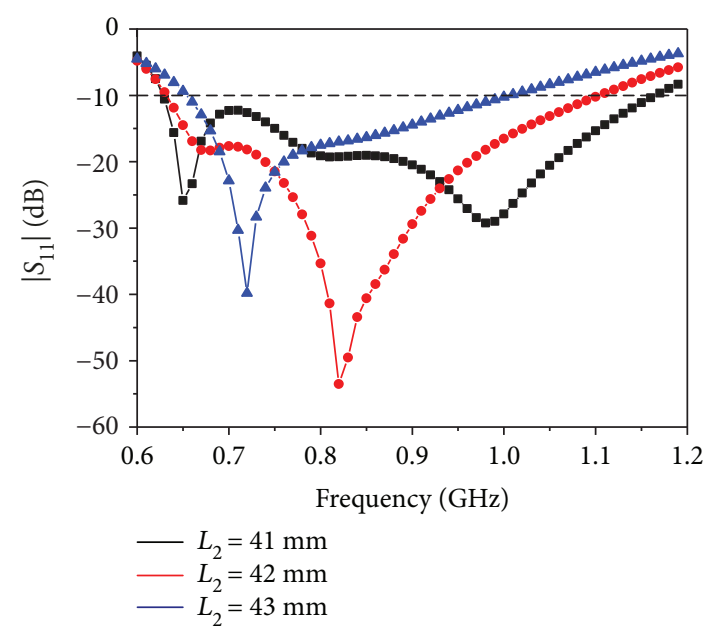

(a)

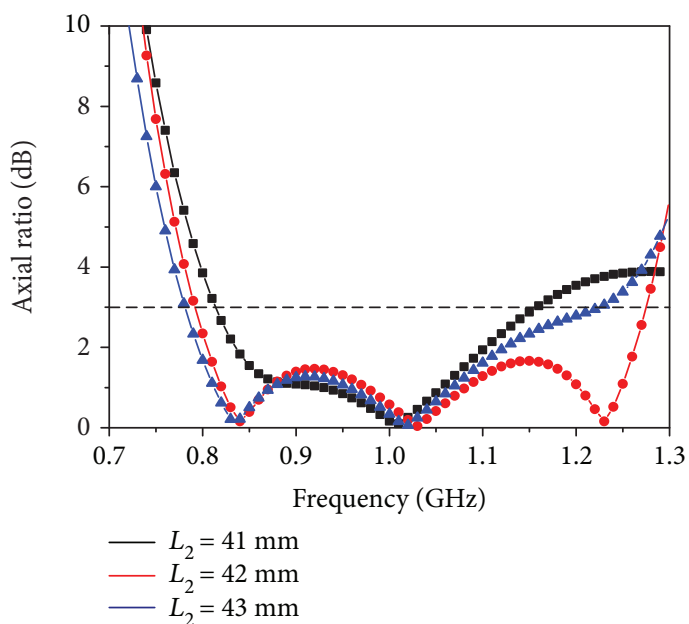

(b)

Figure 7: Simulated $\left|S_{11}\right|$ and AR results for different lengths of the $L_{2}$ parameter.

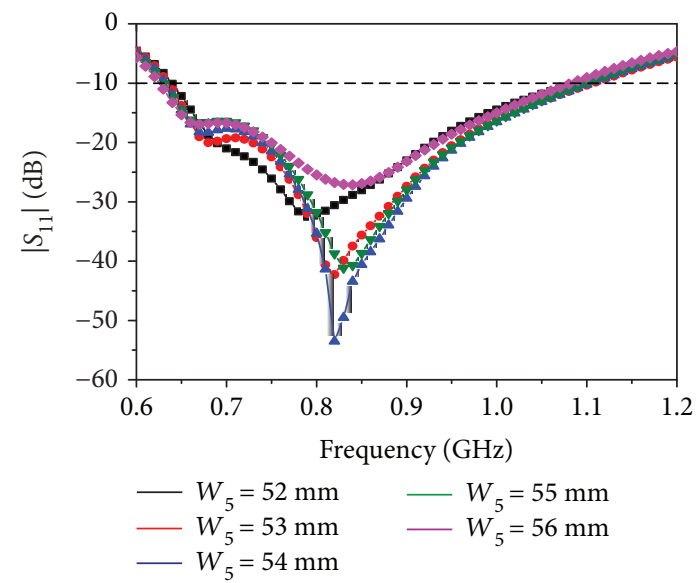

FIGURE 8: Simulated $\left|S_{11}\right|$ for different lengths of the horizontal stub $\left(W_{5}\right)$. ratio bandwidth was achieved at $d_{2}=4.5 \mathrm{~mm}$, as shown in Figure 6(b).

3.3. Influence of the Length $L_{2}$. The effects of tuning the length of the vertical stub of the L-shaped feedline $\left(L_{2}\right)$ from $41 \mathrm{~mm}$ to $43 \mathrm{~mm}$ on the $\left|S_{11}\right|$ and $\mathrm{AR}$ bandwidths are illustrated in Figure 7. As clearly seen in Figure 7(a), the impedance matching and resonance frequency of the reflection coefficient bandwidth increased with the increase in the length of $L_{2}$. The effect of tuning the length $\left(L_{2}\right)$ on the AR bandwidth is demonstrated in Figure 7(b). Although the effect of tuning the length $\left(L_{2}\right)$ from $41 \mathrm{~mm}$ to $43 \mathrm{~mm}$ on the start frequency of the AR band is inconsiderable, the end frequency of the band is increased as the length of $L_{2}$ increased.

It is worth noting that both the impedance matching and resonant frequency of the antenna reflection coefficient $\left|S_{11}\right|$ as well as the AR bandwidth can be controlled by tuning the parameter $L_{2}$. 


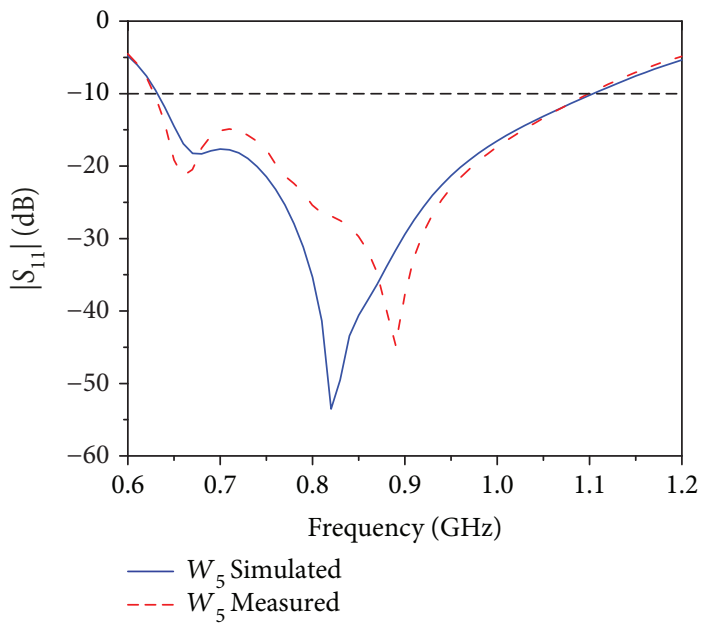

(a)

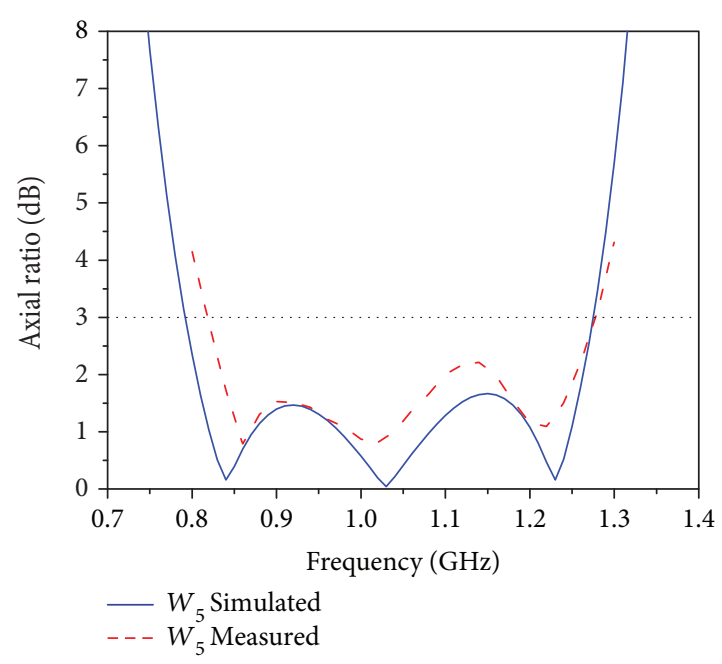

(b)

Figure 9: Measured and simulated (a) $S_{11}$ and (b) AR results of Antenna 4.

3.4. Impedance Matching Reconfigurability. Figure 8 exhibits the influence of tuning the length of the vertical stub $\left(W_{5}\right)$ on the performance of the antenna reflection coefficient. The increase of $W_{5}$ from $52 \mathrm{~mm}$ to $54 \mathrm{~mm}$ improves the impedance matching of the antenna, as shown in Figure 8. However, when $W_{5}$ increased to $55 \mathrm{~mm}$ and $56 \mathrm{~mm}$, the antenna impedance matching is decreased. To achieve the optimal performance of the proposed antenna, the value of the length of $W_{5}$ is adjusted carefully.

\section{Simulation and Measurement Results}

An Agilent E5071C vector network analyzer was used to measure the antenna reflection coefficient $\left|S_{11}\right|$. The farfield performance of the proposed antenna was measured in an anechoic chamber by using the SATIMO measurement system. The measured and simulated reflection coefficient $\left|S_{11}\right|$ results of the proposed compact antenna are demonstrated in Figure 9(a). As shown in the figure, the wide frequency range of both the simulated and measured $10 \mathrm{~dB}$ reflection coefficient $\left|S_{11}\right|$ bandwidths of $54.4 \%$ (632$1104 \mathrm{MHz})$ and $54.6 \%(630-1103 \mathrm{MHz})$ was achieved, respectively. Figure 9 (b) presents the simulated and measured results of the axial ratio bandwidth. Wide simulated and measured axial ratio bandwidths of $484 \mathrm{MHz}$ (792$1276 \mathrm{MHz})$ and $460 \mathrm{MHz}(818-1278 \mathrm{MHz})$ were achieved, respectively. The three $\mathrm{CP}$ frequencies (with the lowest $\mathrm{AR}$ value) were measured at $840 \mathrm{MHz}, 1030 \mathrm{MHz}$, and $1230 \mathrm{MHz}$. As a result of integrating these three CP frequencies, a wide broadband CP bandwidth of $42.4 \%$ $(818-1278 \mathrm{MHz})$ was measured. Good agreement was observed between the simulated and measured results of the reflection coefficient $\left|S_{11}\right|$ and axial ratio bandwidths. As shown in Figure 10, the simulated and measured peak gains of the proposed compact antenna were measured in an authorized SATIMO anechoic chamber, and stable gain levels with small variations of $3.65-4.0 \mathrm{dBi}$ throughout the UHF RFID band (840-960 MHz) can be observed. The

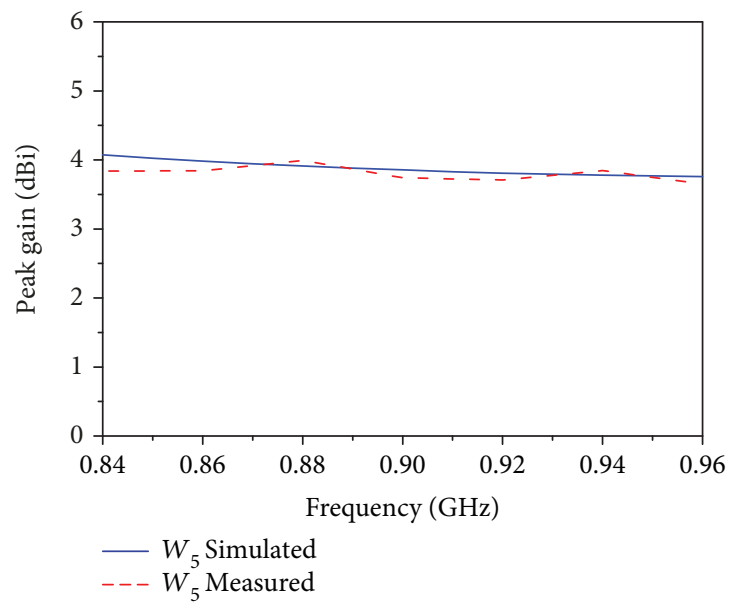

FIGURE 10: Simulated and measured peak gains of the proposed antenna.

maximum measured peak gain of the antenna was at $880 \mathrm{MHz}$. The normalized simulated and measured radiation patterns in both $x-z$ and $y-z$ planes at $900 \mathrm{MHz}$ (centre frequency of the universal UHF RFID band) are presented in Figure 11, and good agreements between them were observed.

The reading-range measurement of the proposed novel compact CP antenna which was accomplished by rotating the Alien dipole-like tag AZ9662 with dimensions of $70 \mathrm{~mm} \times 17 \mathrm{~mm}$ along the $\pm z$-axis direction is depicted in Figure 12. The proposed reader antenna was connected to a UHF RFID reader module (JRM2030) with a low output power of $27 \mathrm{dBm}$ and an operating frequency of $902-$ $928 \mathrm{MHz}$. The antenna exhibited a maximum measured reading range in free space which is maintained between 3.0 and 3.5 meters.

Photographs of the fabricated antenna experiment using the Agilent E5071C vector network analyzer and the SATIMO measurement system are depicted in Figures 13(a) and 13(b), 


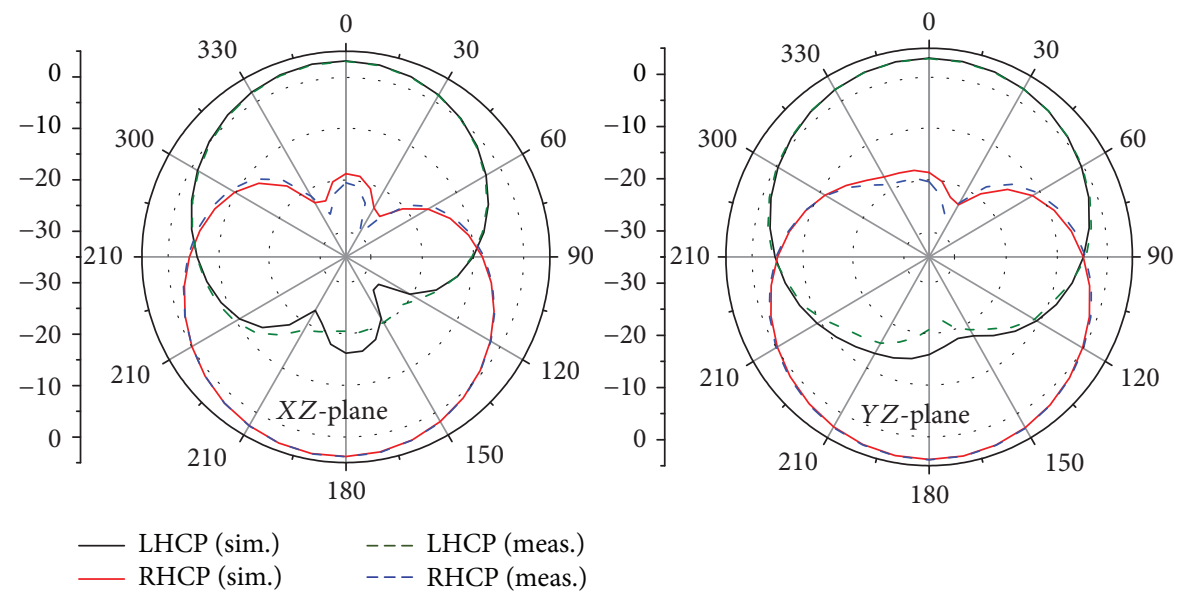

FIgURE 11: Simulated and measured radiation patterns at $900 \mathrm{MHz}$.

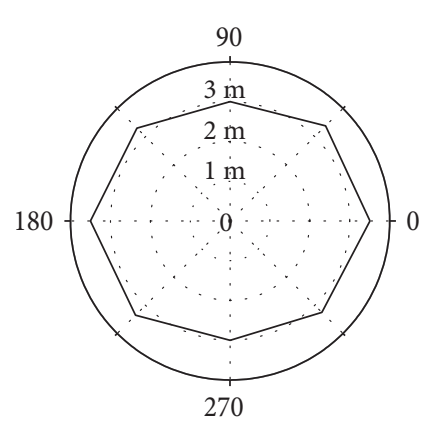

(a)

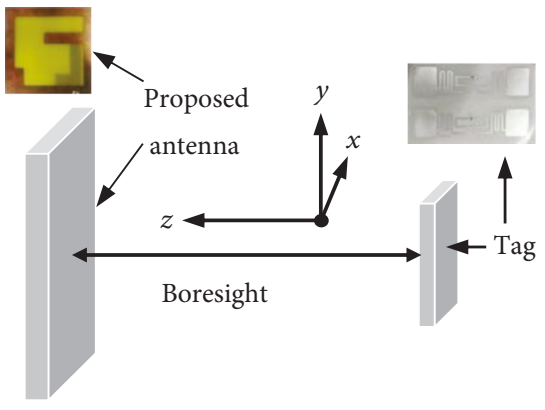

(b)

FIgURE 12: Measured reading ranges for the tag rotating in the $\pm z$-axis.

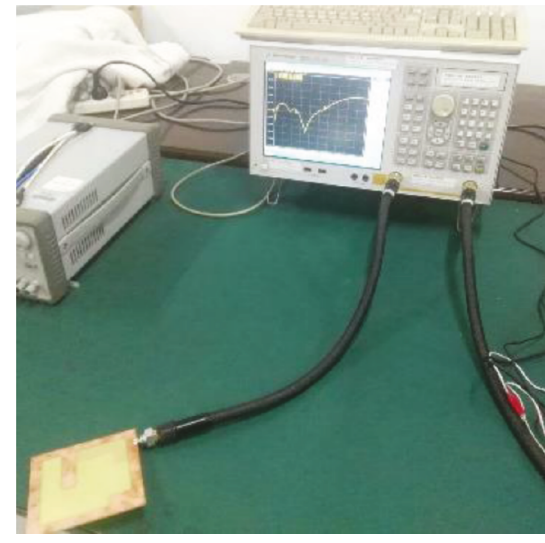

(a)

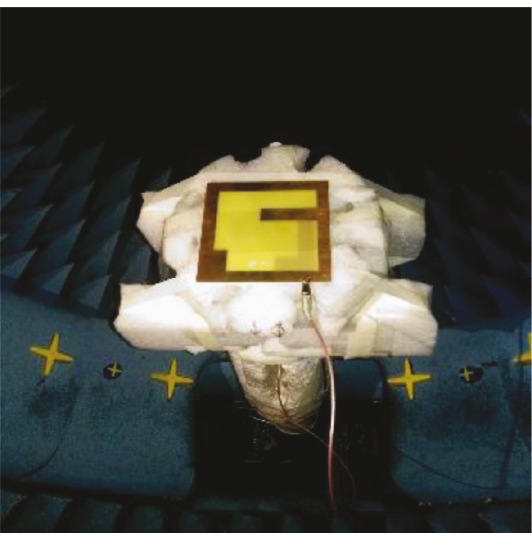

(b)

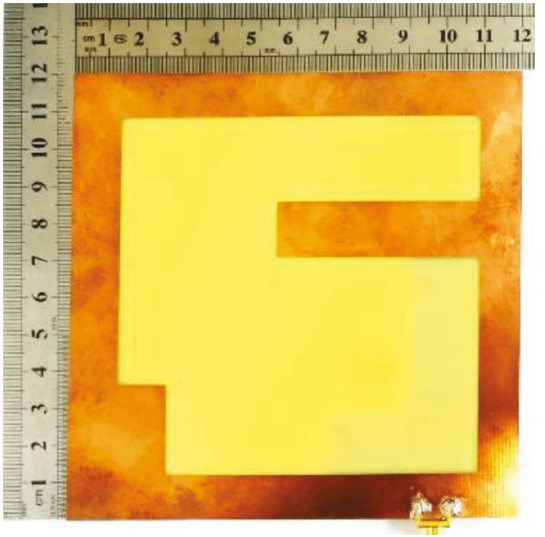

(c)

Figure 13: Fabricated antenna experiment using (a) the E5071C VNA and (b) the SATIMO measurement system. (c) Photograph of the proposed antenna.

respectively. Figure 13(c) shows a photograph of the fabricated antenna. Table 2 exhibits a comparison between the proposed antenna and the antennas which were designed in references [8-14]. As clearly seen in this table, the overall size of the proposed antenna is small, the CP bandwidth is much wider, and the impedance bandwidth of the proposed antenna is much wider compared to all antennas presented in Table 2. The proposed antenna is composed of one ground plane layer, while the antennas in [8-11] consisted of more than one ground plane layer. Notably, the proposed universal UHF RFID antennas covered the entire UHF RFID band of 840$960 \mathrm{MHz}$ in terms of impedance and axial ratio bandwidths, whereas the antennas in $[8-10,12,13,15,16]$ cannot be considered as a universal antenna type $(840-960 \mathrm{MHz})$. 
TABLE 2: Comparison between the proposed antenna and other CP reader antennas.

\begin{tabular}{|c|c|c|c|c|c|}
\hline Ant. & $\begin{array}{c}-10 \mathrm{~dB}\left|S_{11}\right| \\
\mathrm{BW} \\
(\mathrm{MHz} / \%)\end{array}$ & $\begin{array}{c}3 \mathrm{~dB} \text { AR } \\
\text { BW } \\
(\mathrm{MHz} / \%)\end{array}$ & $\begin{array}{l}\text { Max. } \\
\text { gain } \\
(\mathrm{dBi})\end{array}$ & $\begin{array}{c}\text { Sizes } \\
(L \times W \times H) \\
\left(\mathrm{mm}^{3}\right)\end{array}$ & $\begin{array}{c}\text { No. } \\
\text { of } \\
\text { layers }\end{array}$ \\
\hline [8] & $\begin{array}{c}140 \\
835-975\end{array}$ & $\begin{array}{c}70 \\
870-940\end{array}$ & 5.0 & $124 \times 117 \times 33.2$ & 2 \\
\hline [9] & $\begin{array}{c}194 \\
768-962\end{array}$ & $\begin{array}{c}141 \\
816-957\end{array}$ & 9.8 & $250 \times 250 \times 35$ & 4 \\
\hline$[10]$ & $\begin{array}{c}220 \\
880-1100\end{array}$ & $\begin{array}{c}29 \\
901-930\end{array}$ & 7.3 & $150 \times 150 \times 34$ & 2 \\
\hline [11] & $\begin{array}{c}180 \\
800-980\end{array}$ & $\begin{array}{c}180 \\
820-1000\end{array}$ & 6.5 & $250 \times 250 \times 17.3$ & 4 \\
\hline [12] & $\begin{array}{c}225 \\
758-983\end{array}$ & $\begin{array}{c}121 \\
838-959\end{array}$ & 8.6 & $250 \times 250 \times 36.5$ & 4 \\
\hline [13] & $\begin{array}{c}142 \\
860-1002\end{array}$ & $\begin{array}{c}166 \\
857-1023\end{array}$ & 6.8 & $126 \times 121 \times 0.8$ & 1 \\
\hline$[14]$ & $\begin{array}{c}380 \\
618-998\end{array}$ & $\begin{array}{c}332 \\
791-1123\end{array}$ & 3.4 & $120 \times 120 \times 0.8$ & 1 \\
\hline$[15]$ & $\begin{array}{c}90 \\
851-941\end{array}$ & $\begin{array}{c}19 \\
902-921\end{array}$ & 1.4 & $60 \times 60 \times 0.508$ & 1 \\
\hline$[16]$ & $\begin{array}{c}185 \\
794-979\end{array}$ & $\begin{array}{c}60 \\
900-960\end{array}$ & 1.58 & $80 \times 80 \times 1.6$ & 1 \\
\hline $\begin{array}{l}\text { Our } \\
\text { work }\end{array}$ & $\begin{array}{c}473 \\
630-1103\end{array}$ & $\begin{array}{c}460 \\
818-1278\end{array}$ & 4.0 & $120 \times 120 \times 1.6$ & 1 \\
\hline
\end{tabular}

\section{Conclusion}

In this study, a new reader antenna for universal UHF RFID handheld applications was demonstrated and experimentally investigated. The proposed antenna consists of a CPW Lshaped feedline mounted at the right edge of the square slot at the bottom of the ground plane, with a horizontal stub protruding from the right side of the square and a vertical stub placed at the lower left of the square slot. The positions and geometries of these L-shaped feedlines and stubs are carefully adjusted to obtain a wide CP bandwidth. The proposed antenna shows a measured impedance bandwidth of $54.6 \%(630-1103 \mathrm{MHz})$ with a reflection coefficient less than $-10 \mathrm{~dB}$, a $3 \mathrm{~dB}$ axial ratio bandwidth of $460 \mathrm{MHz}(818-$ $1278 \mathrm{MHz}$ ), and a stable radiation gain between 3.65 and $4.0 \mathrm{dBi}$ throughout the universal UHF RFID band (840$960 \mathrm{MHz}$ ). The proposed antenna has the merits of compact size, simple structure, easy fabrication process, and wide axial ratio bandwidth compared to the reader antennas mentioned in Table 2. The measured antenna performances mentioned above indicate that the proposed antenna easily satisfies the requirements of the universal UHF RFID handheld reader antenna applications with a wide axial ratio bandwidth and a compact overall size of only $120 \times 120 \times 1.6 \mathrm{~mm}^{3}$.

\section{Data Availability}

The simulated and measured results for each parameter are plotted in one figure as a comparison between the simulation and measurement results.

\section{Conflicts of Interest}

The authors declare that there is no conflict of interest regarding the publication of this paper.

\section{Acknowledgments}

This work is supported by the Key Project of the National Natural Science Foundation of China under Grants 61531016 and 61831017 and the Sichuan Provincial Science and Technology Important Projects under Grants 2018GZ0139 and 2018GZDZX0001.

\section{References}

[1] A. Ren, C. Wu, Y. Gao, and Y. Yuan, "A robust UHF near-field RFID reader antenna," IEEE Transactions on Antennas and Propagation, vol. 60, no. 4, pp. 1690-1697, 2012.

[2] J. K. Pakkathillam, M. Kanagasabai, and M. G. N. Alsath, "Compact multiservice UHF RFID reader antenna for nearfield and far-field operations," IEEE Antennas and Wireless Propagation Letters, vol. 16, pp. 149-152, 2017.

[3] Q. Liu, J. Shen, J. Yin, H. Liu, and Y. Liu, "Compact 0.92/2.45GH dual-band directional circularly polarized microstrip antenna for handheld RFID reader applications," IEEE Transactions on Antennas and Propagation, vol. 63, no. 9, pp. 38493856, 2015.

[4] T. Wu, H. Su, L. Gan, H. Chen, J. Huang, and H. Zhang, "A compact and broadband microstrip stacked patch antenna with circular polarization for 2.45-GHz mobile RFID reader," IEEE Antennas and Wireless Propagation Letters, vol. 12, pp. 623-626, 2013.

[5] W.-S. Chen and Y.-C. Huang, "A novel CP antenna for UHF RFID handheld reader," IEEE Antennas and Propagation Magazine, vol. 55, no. 4, pp. 128-137, 2013.

[6] M. H. Hoang, T. Q. Van Hoang, H. P. Phan, and T. P. Vuong, "Cavity-backed circular-polarized compact slot antenna for handheld UHF RFID reader," IEEE Antennas and Wireless Propagation Letters, vol. 14, pp. 1439-1442, 2015.

[7] Nasimuddin, Z. N. Chen, and X. Qing, "Asymmetric-circular shaped slotted microstrip antennas for circular polarization and RFID applications," IEEE Transactions on Antennas and Propagation, vol. 58, no. 12, pp. 3821-3828, 2010.

[8] T.-N. Chang and J.-M. Lin, "Circularly polarized ring-patch antenna," IEEE Antennas and Wireless Propagation Letters, vol. 11, pp. 26-29, 2012.

[9] X. Liu, Y. Liu, and M. M. Tentzeris, “A novel circularly polarized antenna with coin-shaped patches and a ring-shaped strip for worldwide UHF RFID applications," IEEE Antennas and Wireless Propagation Letters, vol. 14, pp. 707-710, 2015.

[10] C.-Y.-D. Sim and C.-J. Chi, "A slot loaded circularly polarized patch antenna for UHF RFID reader," IEEE Transactions on Antennas and Propagation, vol. 60, no. 10, pp. 4516-4521, 2012.

[11] H. L. Chung, X. Qing, and Z. N. Chen, "A broadband circularly polarized stacked probe-fed patch antenna for UHF RFID applications," International Journal of Antennas and Propagation, vol. 2007, 8 pages, 2007.

[12] Z. Wang, S. Fang, S. Fu, and S. Jia, "Single-fed broadband circularly polarized stacked patch antenna with horizontally meandered strip for universal UHF RFID applications," IEEE 
Transactions on Microwave Theory and Techniques, vol. 59, no. 4, pp. 1066-1073, 2011.

[13] J.-H. Lu and S.-F. Wang, "Planar broadband circularly polarized antenna with square slot for UHF RFID reader," IEEE Transactions on Antennas and Propagation, vol. 61, no. 1, pp. 45-53, 2013.

[14] R. Cao and S.-C. Yu, "Wideband compact CPW-fed circularly polarized antenna for universal UHF RFID reader," IEEE Transactions on Antennas and Propagation, vol. 63, no. 9, pp. 4148-4151, 2015.

[15] S. X. Ta, H. Choo, and I. Park, "Planar, lightweight, circularly polarized crossed dipole antenna for handheld UHF RFID reader," Microwave and Optical Technology Letters, vol. 55, no. 8, pp. 1874-1878, 2013.

[16] C.-Y. Pan, C.-C. Su, G.-J. Wu, and J.-Y. Jan, "Circularly polarized monopole antenna using short-circuited sleeve strip for UHF RFID reader," Microwave and Optical Technology Letters, vol. 56, no. 4, pp. 957-961, 2014.

[17] M. S. Ellis, Z. Zhao, J. Wu, X. Ding, Z. Nie, and Q.-H. Liu, "A novel simple and compact microstrip-fed circularly polarized wide slot antenna with wide axial ratio bandwidth for C-band applications," IEEE Transactions on Antennas and Propagation, vol. 64, no. 4, pp. 1552-1555, 2016. 


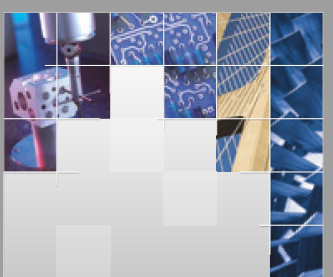

\section{Enfincering}
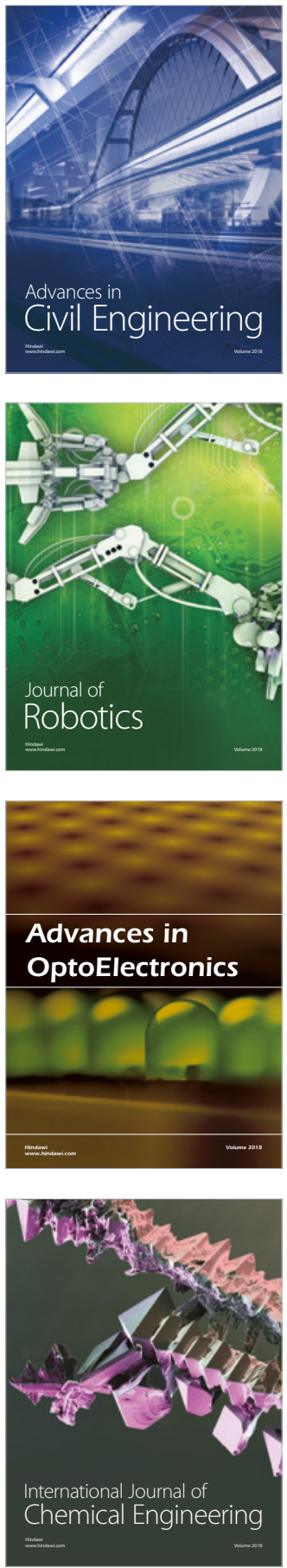

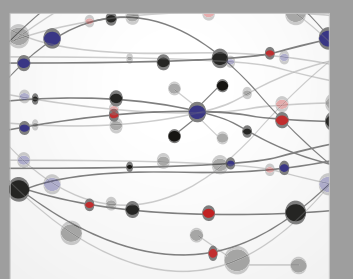

\section{Rotating \\ Machinery}

The Scientific World Journal

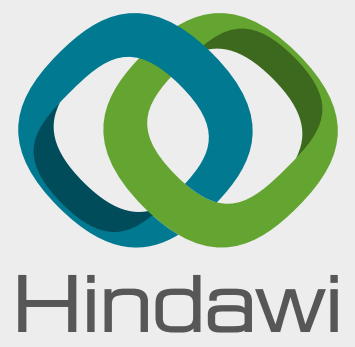

Submit your manuscripts at

www.hindawi.com
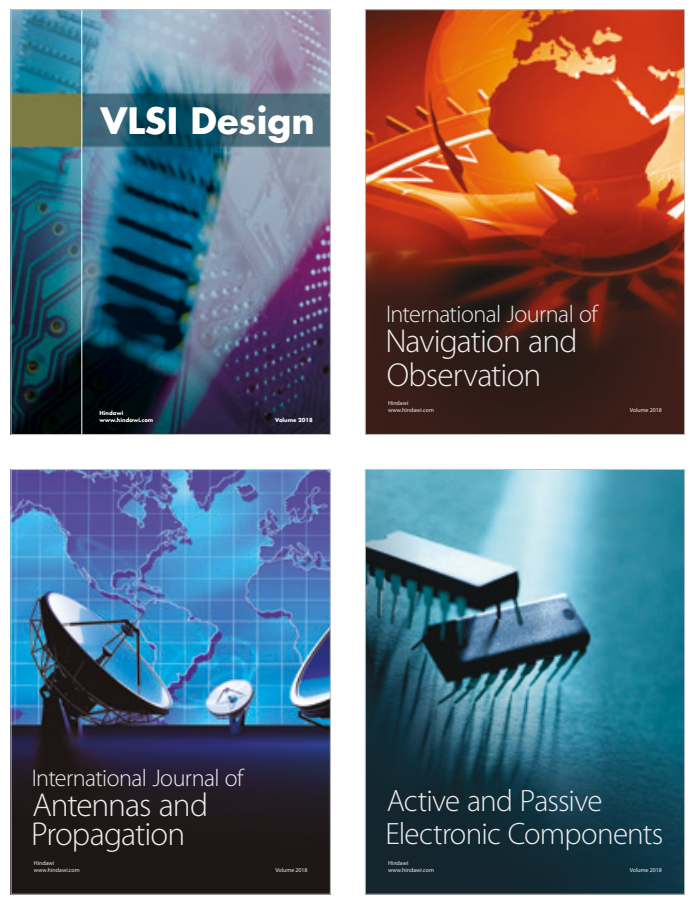
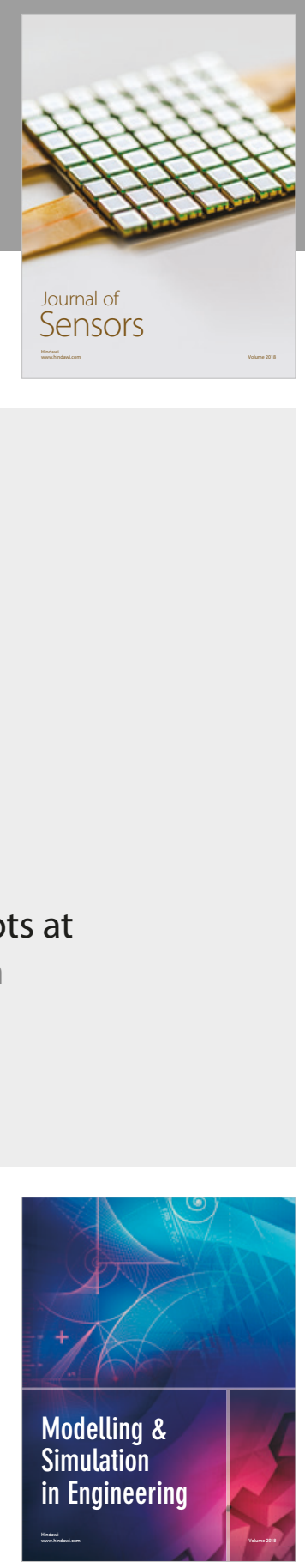

\section{Advances \\ Multimedia}
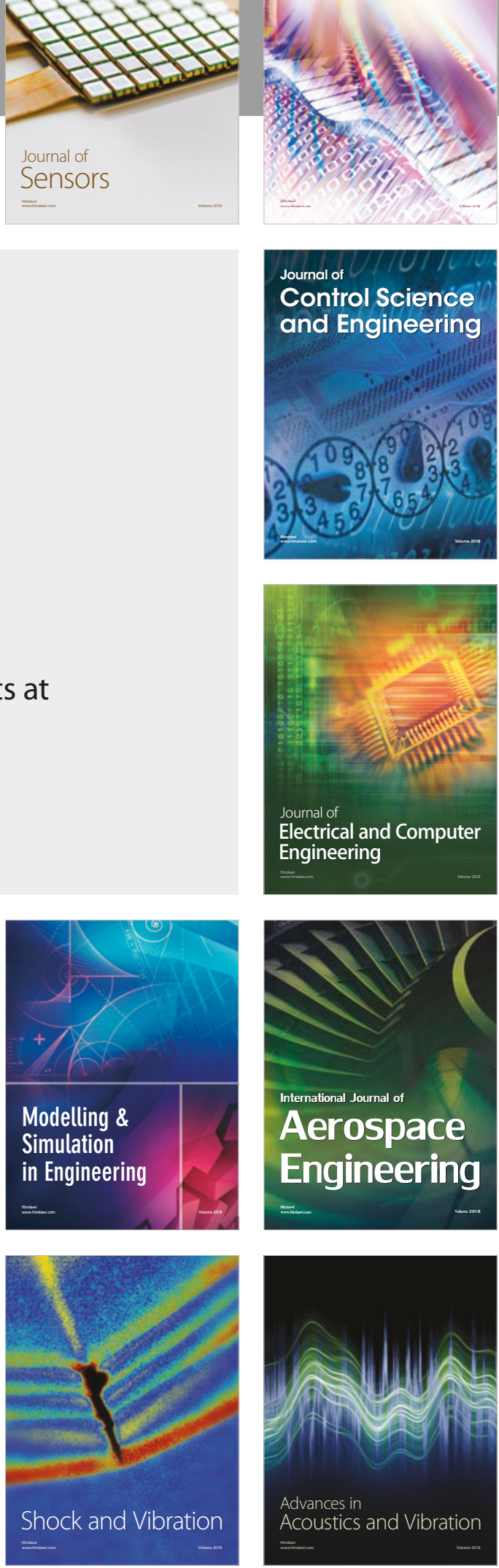